\title{
Heterogeneous freezing of single sulfuric acid solution droplets: laboratory experiments utilizing an acoustic levitator
}

\author{
M. Ettner ${ }^{1}$, S. K. Mitra ${ }^{1}$, and S. Borrmann ${ }^{1,2}$ \\ ${ }^{1}$ Institute for Atmospheric Physics, Johannes Gutenberg-University, Mainz, Germany \\ ${ }^{2}$ Max Planck Institute for Chemistry, Mainz, Germany
}

Received: 23 January 2004 - Published in Atmos. Chem. Phys. Discuss.: 25 March 2004

Revised: 19 July 2004 - Accepted: 22 September 2004 - Published: 29 September 2004

\begin{abstract}
The heterogeneous freezing temperatures of single binary sulfuric acid solution droplets were measured in dependency of acid concentration down to temperatures as low as $-50^{\circ} \mathrm{C}$. In order to avoid influence of supporting substrates on the freezing characteristics, a new technique has been developed to suspend the droplet by means of an acoustic levitator. The droplets contained immersed particles of graphite, kaolin or montmorillonite in order to study the influence of the presence of such contamination on the freezing temperature. The radii of the suspended droplets spanned the range between 0.4 and $1.1 \mathrm{~mm}$ and the concentration of the sulfuric acid solution varied between 5 and 14 weight percent. The presence of the particles in the solution raises the freezing temperature with respect to homogeneous freezing of these solution droplets. The pure solution droplets can be supercooled up to 40 degrees below the ice-acid solution thermodynamic equilibrium curve. Depending on the concentration of sulfuric acid and the nature of the impurity the polluted droplets froze between $-11^{\circ} \mathrm{C}$ and $-35^{\circ} \mathrm{C}$. The new experimental set-up, combining a deep freezer with a movable ultrasonic levitator and suitable optics, proved to be a useful approach for such investigations on individual droplets.
\end{abstract}

\section{Introduction}

Sulfuric acid is one of the major components of existing particles in the upper troposphere (UT) and lower stratosphere (LS) (Sheridan et al., 1994; Murphy et al., 1998). The emission of sulfur containing gases and their subsequent oxidation produces $\mathrm{H}_{2} \mathrm{SO}_{4}$ in the atmosphere. Droplets, consisting of sulfuric acid/water solution, are often found in a supercooled metastable state.

Correspondence to: $\mathrm{M}$. Ettner

(ettner@mpch-mainz.mpg.de)
The atmosphere contains aerosol particles, which could contaminate the aqueous droplets and therefore cause heterogeneous contact or immersion freezing. Clay minerals and carbonaceous particles were often found in the upper troposphere and lower stratosphere (Mason, 1960; Hoffer, 1961; Pueschel et al., 1992). Ice nucleation of water in the immersion and contact mode caused by these particles, has been studied by Mason, 1960; Hoffer, 1961; Pitter and Pruppacher, 1973; Diehl et al., 1998. Also the influence of biogenic materials as pollen and bacteria on the freezing behaviour of solution droplets was measured by (Diehl et al., 2002; von Blohn, 2003).

Emissions of soot particles and sulphate aerosol in the upper troposphere/lower stratosphere by aircraft engines cause the formation of contrails. Such contrails influence the radiative forcing of the atmosphere by reducing the solar radiation and trapping parts of the longwave radiation from earth's surface (Penner et al., 1999). They also have an effect on cirrus cloud formation because gas phase and particulate emissions as well as long-lived contrails sometimes contribute to the formation or persistence of cirrus clouds.

Binary heterogeneous nucleation and condensation produces a coating of liquid $\mathrm{H}_{2} \mathrm{SO}_{4} / \mathrm{H}_{2} \mathrm{O}$ on soot particles emitted by aircraft engines. These particles grow by condensation of gaseous $\mathrm{H}_{2} \mathrm{O}$ and $\mathrm{H}_{2} \mathrm{SO}_{4}$ and also by coagulation with volatile $\mathrm{H}_{2} \mathrm{SO}_{4} / \mathrm{H}_{2} \mathrm{O}$ particles forming a mixed $\mathrm{H}_{2} \mathrm{SO}_{4} / \mathrm{H}_{2} \mathrm{O}$ soot aerosol. These may also contain polycyclical organic compounds (Penner et al., 1999). The emitted soot particles are agglomerates of up to several hundreds of small, primary graphite spheres with size diameters roughly between 10 and $50 \mathrm{~nm}$. The structure of these primary particles has been shown to be graphitic (Charlson and Ogren, 1982; Burtscher, 1992; Lahaye, 1992). Freezing of those particles creates ice particles which form the visible part of the contrails.

The transition from the liquid into the ice phase takes place either through heterogeneous ice nucleation at the interface of the nucleus and the liquid, or by homogeneous nucleation 


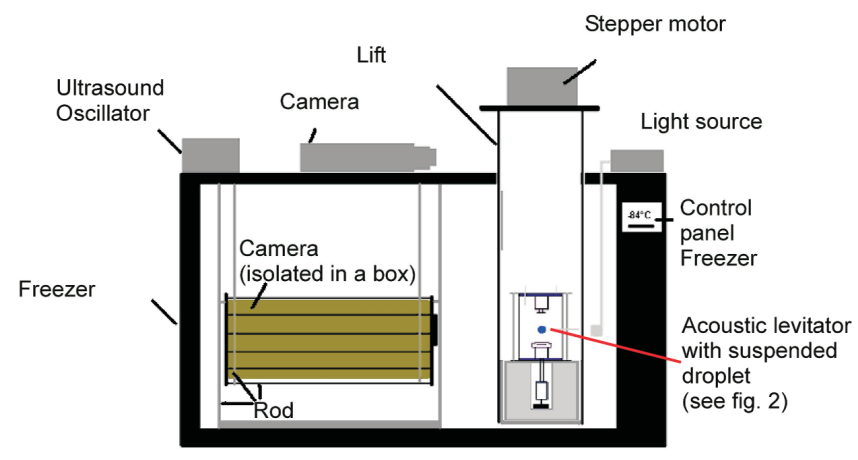

Fig. 1. Chest freezer with the movable acoustic levitator.

occuring in the interior of the liquid. Here it needs to be mentioned, that some recent theoretical studies indicate that the surface of the liquid is a possible site for the initiation of homogeneous nucleation (Tabazadeh et al., 2002). This theory has sparked a big controversy (Kay et al., 2003 and discussions).

In the past, numerous studies have been carried out to investigate the homogeneous nucleation of sulfuric acid/water solutions (Bertram et al., 1996; Carleton et al., 1997; Koop et al., 1997, 1998; Krämer, 1998; Prenni et al., 1999; Vortisch et al., 2000). According to these, homogeneous ice nucleation occurs at temperatures significantly below the equilibrium temperature where ice and sulfuric acid solution co-exist.

Heterogeneous ice nucleation efficiencies of soot, solid $\left(\mathrm{NH}_{4}\right)_{2} \mathrm{SO}_{4}$, solid $\mathrm{NH}_{4} \mathrm{HSO}_{4}$ kaolinite and montmorillonite have been recently reported in the literature (DeMott et al., 1990, 1999; Zuberi et al., 2001, 2002). Studies on the heterogeneous nucleation of $\mathrm{H}_{2} \mathrm{SO}_{4} / \mathrm{H}_{2} \mathrm{O}$ droplets on substrates such as gold have been reported in the literature (Martin et al., 1997). Also, mineral dust induced heterogeneous freezing of $\left(\mathrm{NH}_{4}\right)_{2} \mathrm{SO}_{4}$ droplets have been studied (Hung et al., 2003).

In this paper, we present laboratory measurements of the freezing behaviour of single, large sulfuric acid/water droplets obtained by using an acoustic levitator in connection with a deep freezer. This technology is briefly described and measured results are presented for homogeneous and heterogeneous freezing temperatures in the immersion mode. Here the freezing was triggered by insoluble particles consisting of either kaolin, or montmorillionite or graphite (as proxy for soot) which were added to the droplets. The diameter of the suspended droplets ranged between $800 \mu \mathrm{m}$ and $2.2 \mathrm{~mm}$ and hence were orders of magnitudes larger than the sub-micron to micron sized droplets typically present in the UT/LS. This size range was chosen for the experiments, because the larger drop volumes ensure the observation of a freezing event within a reasonable short time period. In other words, the "volume advantage" is expected to reduce observation time until a freezing event occurs. Furthermore within this size range evaporation losses of the solution droplet during the observation period are minimised.

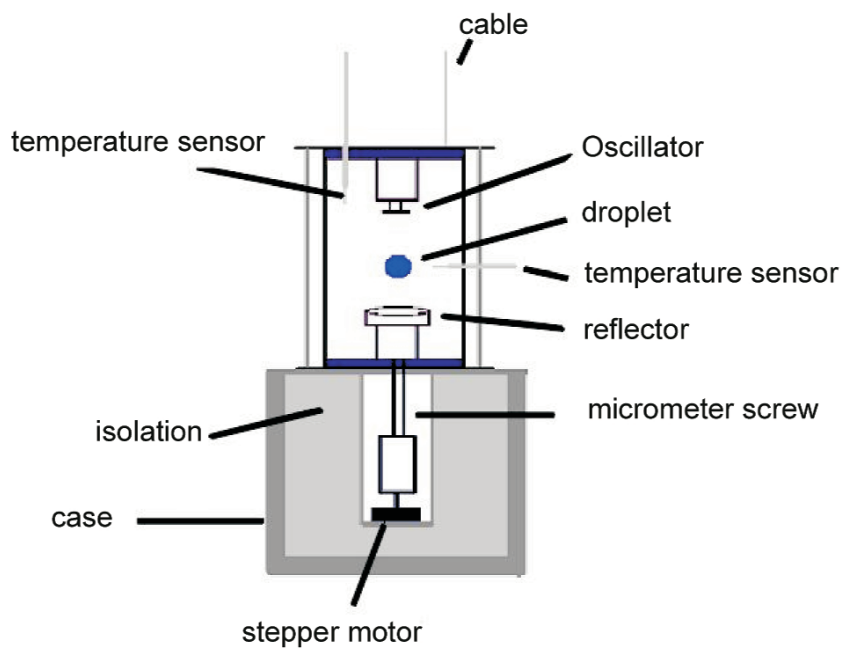

Fig. 2. Acoustic levitator with suspended droplet.

\section{Experimental methodology}

The experimental set-up is shown in Fig. 1. A large chest freezer, which can be cooled down to $-85^{\circ} \mathrm{C}$, houses the closed chamber with the acoustic levitator. Using an elevator mechanism, the levitator unit can be moved from outside of the freezer to its bottom, where the lowest temperatures are encountered. Two CCD-cameras record images of the droplet onto a video tape. One camera is positioned on the top of the freezer, where it records the injection of the droplet into its floating position at an acoustic node. The other CCDcamera is located inside the chest freezer and is protected by a thermally isolated and heated box to ensure its operation at these temperature extremes. The oscillatory motion in the standing sound wave field and the evaporation of the droplet during its cooling down to the freezing point can be visually observed on a monitor and later analysed.

As long as the levitator is moving down to the bottom of the freezer, no images of the sample can be taken and for this time period of about 2-3 min, the droplet can not be observed. During this period the droplet position can not be externally controlled, which leads to frequent losses of droplets.

The acoustic levitator device used to freely suspend the droplets is shown in Fig. 2.

Inside the acoustic levitator a piezoelectric oscillator (radiator) generates a sound wave at $58 \mathrm{kHz}$, which is reflected by a concave Teflon reflector. With proper positioning of the reflector, standing waves are produced in the space between the radiator and the reflector. A droplet with a diameter up to $3 \mathrm{~mm}$ or as small as $100 \mu \mathrm{m}$ can be levitated in a vertical position slightly below the third of the five existing nodes. As the acoustic field strength required to suspend the droplets increases quadratically with its weight, very large droplets can not be levitated. Smaller droplets will evaporate rapidly 
Table 1. Characteristics of the instrumental setup.

\begin{tabular}{lll}
\hline & Applied for this study & Experimentally possible \\
\hline Droplet size [mm] & $0.8-2.2$ & $0.1-3$ \\
Concentration range [wt $\%]$ & $5-14$ & $0-100$ \\
Measurement time [hours] & $0.5-4$ & 0 -unlimited \\
\hline
\end{tabular}

and cannot be seen clearly with the current magnification of the cameras.

The experimental characteristics are summarised in Table 1 . The gravitation force $F_{\text {Grav }}$ (in $N$ ) is in balance with the axial levitation force $F_{L e v}$ (in $N$ ) and the droplet is kept afloat there in a stable position. If the droplet moves horizontally, the gas flow on the side of the droplet towards the levitation axis is higher then on its other side. The resulting underpressure forces the droplet back into its original, stable position. The balance of forces is described by the following equation:

$F_{\text {Lev }}=\frac{5}{6} k \pi \frac{p^{2}}{\rho_{0} c_{0}^{2}} r_{d}^{3} \sin (2 k \Delta z)=-\frac{4}{3} \pi r_{d}^{3} \rho_{d} g=-F_{\text {Grav }}$

The wave number of the sound wave is denoted by $k$ in $1 / \mathrm{m}, p$ is the amplitude of sound pressure in $\mathrm{N} / \mathrm{m}^{2}, r_{d}$ the radius of the drop in $\mathrm{m}, c_{0}$ the speed of sound in $\mathrm{m} / \mathrm{s}, \rho_{0}$ and $\rho_{d}$ the density of air (0) and the density of the droplet (d) in $\mathrm{kg} / \mathrm{m}^{3} . \Delta z$ is the vertical displacement from the exact nodal position, and $g$ is the gravitational acceleration in $\mathrm{m} / \mathrm{s}^{2}$. The operator controls a micrometer screw by means of a stepper motor, which is used to move the reflector in order to change the distance between the oscillator-radiator and the reflector. This is necessary, because with decreasing temperature the speed of sound and with it the wavelength and thus the separation between the nodes change. This variation can be compensated with an appropriate reduction of the distance between the radiator and the reflector. For this reason the operator has to observe the droplet using the video images and adjust the nodal positions. The micrometer screw has to be heated, because otherwise the lubricating oil will freeze blocking any adjustments. In order to avoid fast temperature changes, the trap is surrounded by a Plexiglas hood. Fluctuating temperatures will otherwise lead to an irreversible deviation of the droplet from its equilibrium position because of the inherent slow operator response time for readjusting the nodal positions resulting a loss of the droplets. A Pt100 sensor next to the floating droplet allows one to measure a proxy for the droplet temperature. The ultrasonic fields heat the droplet by approximately $2^{\circ} \mathrm{C}$. The heating of the droplet due to the ultrasonic field was measured by means of a thermocouple. A thermocouple was placed at the tip of a droplet and it was positioned in the ultrasonic field. This measured temperature was always approximately $2^{\circ} \mathrm{C}$ higher than the temperature measured with the Pt-100 sensor, which

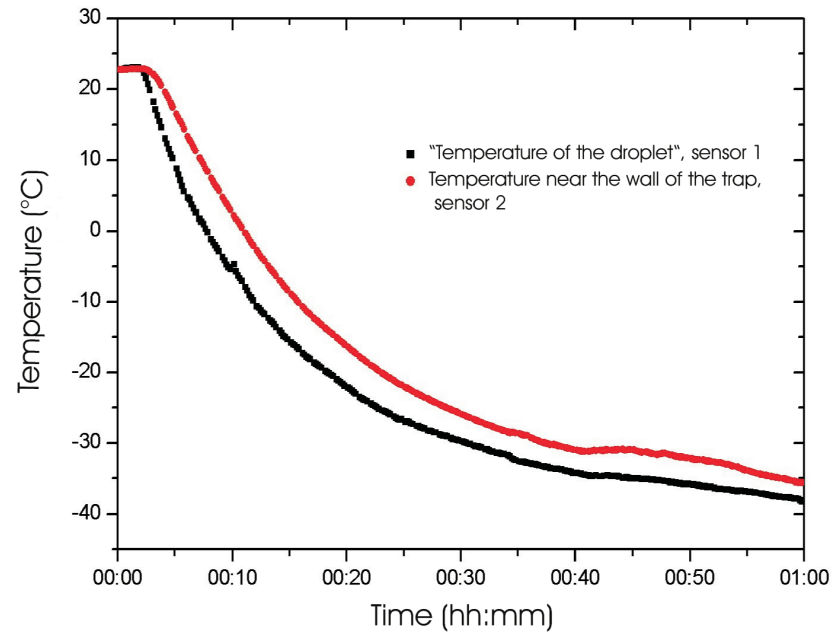

Fig. 3. Temperature decrease inside the Plexiglas trap.

was positioned next to the droplet for the whole range of temperatures. The Pt-100 sensor was the sensor we used during our real experiment, and we concluded that the "real" droplet temperature is the Pt-100 value corrected by $2^{\circ} \mathrm{C}$. A second temperature sensor is positioned very close to the wall of the Plexiglas hood to obtain a measure of the temperature at the significant distance away from the droplet. The presence of the Plexiglas hood allows the temperature of the drop to decrease at a controlled rate thus ensuring the droplet's continuous levitation. A typical temperature record from an experiment is shown in Fig. 3.

Both temperatures decrease, when the acoustic levitator is moved into the freezer. They approach the temperature of the freezer in a certain time, depending on the pre-set freezer temperature. The "droplet temperature" measured with sensor 1, which is illustrated with the red line in Fig. 3, is corrected by $2^{\circ} \mathrm{C}$, considering the warming caused by the ultrasonic field. The temperature recorded by sensor 1 in the moment when freezing occurs is regarded as the freezing temperature of the droplet.

At the beginning of the experiment a syringe with a special needle is used to place the solution droplet at the ultrasonic standing wave node, where it is levitated. The needle is teflon-coated to ensure easy detachment of the drop from its tip.

By means of this levitation-technique, we were able to experiment with droplets in the $\mathrm{mm}$ size range. Although this relatively large size reduces the effect of evaporation loss, the volume decrease is not negligible. Especially in the beginning of the experiment, the solution is exposed to warmer ambient temperatures, which cause faster evaporation.

To monitor the changing droplet volume continuously during an experiment, the video images were digitized. In post-processing of each freezing experiment the height and the width of the droplets were determined using the digital 

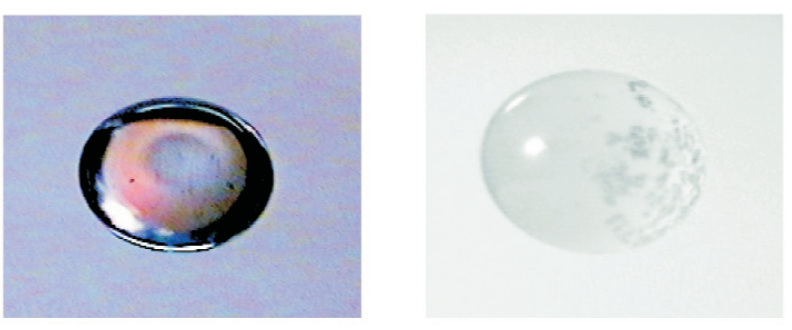

Fig. 4. Left: liquid droplet with a few graphite particles inside. Right: frozen droplet with graphite particles on the surface.

images while assuming the droplets to have the shape of rotationally symmetric ellipsoids. Taking this into account the droplet volumes could be obtained from the digitized video images. The assumption of the rotationally symmetric shape of a levitated droplet can be confirmed visually.

Examples for typical droplet images are given in Fig. 4. The left picture shows an unfrozen, liquid sulfuric acid solution droplet containing black graphite particles. The particles inside the liquid move around due to internal circulation of the droplet induced by sound generated airflow around it. That means they are moving in and out of the surface. In the case of graphite particles most particles seem to be on the surface after freezing, because the graphite particles show up prominently against the ice backround. For other substances the contrast between the particle and the ice backround is not so high. The large dark and the white areas result from reflections and refractions from parts of the experimental apparatus. The image to the right shows a frozen droplet with graphite particles on its surface. The transition from the liquid to the solid phase is easily detected from the rapid change of the drop image from transparent to opaque.

Sulfuric acid solutions with initial concentrations of 5 , 9 and $11 \mathrm{wt} \%$ were investigated. Water from the solution droplets evaporates during each experiment. With the assumption that no $\mathrm{H}_{2} \mathrm{SO}_{4}$ evaporates, the concentration of sulfuric acid in the solution increases during the experiment. The actual concentration in the droplet can be calculated with the known decrease of the volume and the density of the solution at the particular temperature (Luo et al., 1996).

To obtain the concentration at the moment of freezing, the volume right before the phase transition is obtained. From the 25 frame-per-second video, the drop volumes were obtained which together with the knowledge of the density of the solutions lead to the determination of the sulphuric acid concentration in the drop.

To investigate heterogeneous ice nucleation, various commercially available materials (Sigma Aldrich) were added to the solution droplets. The investigated materials, namely graphite, kaolin, montmorillonite KSF and montmorillonite $\mathrm{K} 10$, were all obtained in very fine powdered form. The particles were introduced into the droplet simply by dipping the needle tip into the respective substance and then squeezing a

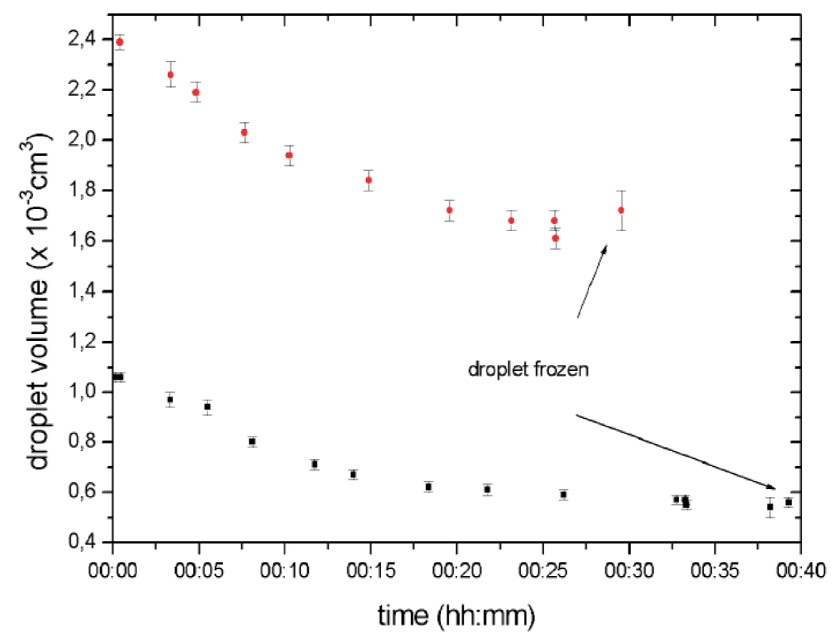

Fig. 5a. Volume decrease of two uncontaminated droplets with different initial size.

volume of the liquid into the acoustic node. The disadvantage of this technique is, that we were not able to determine the number of particles present in the droplet.

\section{Sources of errors}

The homogeneous freezing temperature of a liquid depends on the purity of the solution. In order to obtain homogeneous ice nucleation it is of great importance to ensure a high purity of the solution. Because the suspended droplet is more or less exposed to the ambient atmosphere, particles and gases are able to contaminate the solution.

The same precautions are also required for experiments on heterogeneous nucleation. Furthermore, the indefinable number of particles which are brought into the droplet, may influence the freezing behaviour of the droplets. Further technical refinements are currently being implemented in order to reduce these effects.

The accuracy of the temperature measurement is $1^{\circ} \mathrm{C}$. The error in size determination of the droplet leads to an uncertainty of the volume, which is lower than 5\%. The volume error leads to an uncertainty in the calculation of the sulfuric acid concentration.

\section{Results}

Figure 5a shows a typical volume decrease of 2 droplets during exposure inside the trap where the droplet size decreases with time due to evaporation loss of water. This evaporation loss slows down as the temperature of the drop falls with time. At the moment of freezing, the volume of the droplets shows a small jump, which is caused by the transition from the liquid phase to the ice phase. The evaporation of $\mathrm{H}_{2} \mathrm{O}$ does lead to a cooling of the droplets, especially during the 


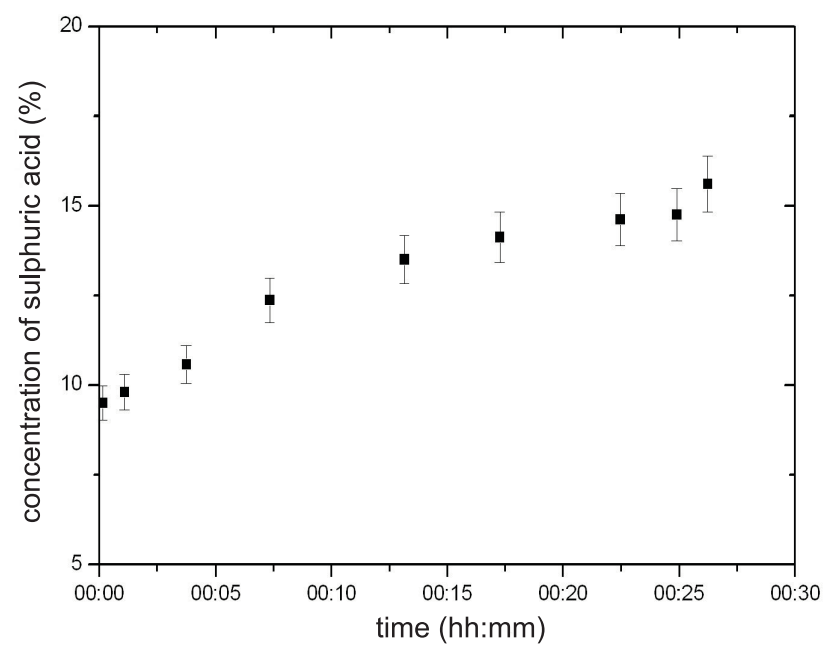

Fig. 5b. Increase of the sulphuric acid concentration.

first few minutes of the experiment. However, the volume decrease slows down with time, as shown in Fig. 5a. At the moment of freezing, the rate of evaporation is extremely low and evaporative cooling can be neglected.

Figure $5 \mathrm{~b}$ shows a typical increase of the calculated sulfuric acid concentration in the solution droplet with time, caused by the evaporation of water. The error bars result from the uncertainties in the volume measurements. The heterogeneous freezing temperatures in the immersion mode, measured with the ultrasonic levitator device, were higher compared to the homogeneous freezing temperatures of the pure liquid.

Figures 6 and 7 show the freezing temperatures of the single sulfuric acid solution droplets in relation to their concentration. The red circles in Fig. 6 represent the homogeneous freezing of the pure solution. The green triangles show the freezing temperatures of the solution containing inclusions of graphite particles, whereas the blue squares represents those for the solution containing montmorillonite KSF particles. The solid line indicate the phase transition equilibrium between ice and sulfuric acid/water solution (Gable et al., 1950).

Around the homogeneous freezing temperature of the droplets the rate of change of temperature in the experimental set-up was low, about $10^{\circ} \mathrm{C} / \mathrm{hr}$ (Fig. 3). The droplets remained for a few (1-3) minutes at this temperature before they froze. Considering the typical droplet volumes to be of the order of $10^{-3} \mathrm{ml}\left(0.25 \times 10^{-3}-5 \times 10^{-3} \mathrm{ml}\right)$ and the fact that the drops remained around the freezing temperature for a time period between 50 and $200 \mathrm{~s}$ before they freeze, we appoximately estimated the nucleation rates $(\mathrm{J})$ to span a range from $1 \mathrm{~cm}^{-3} \mathrm{~s}^{-1}$ to $100 \mathrm{~cm}^{-3} \mathrm{~s}^{-1}$.

For comparison, we include the parameterization for homogeneous nucleation temperatures of aqueous solutions (Koop et al., 2000), for the two values of $J$, in the figures

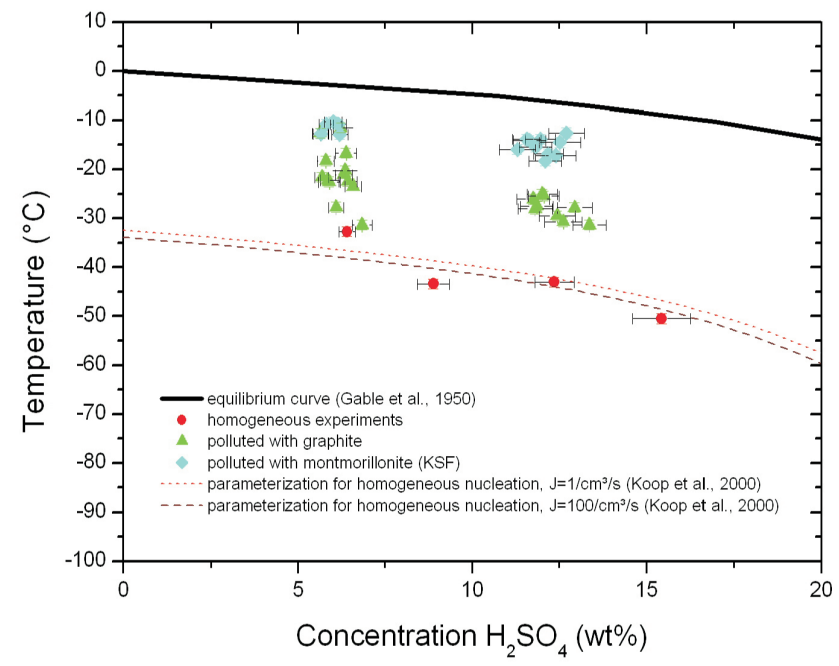

Fig. 6. Freezing temperatures of the sulphuric acid solution versus the concentration in wt $\%$, droplets containing inclusions of graphite and montmorillonite (KSF) compared to the pure solution together with the equilibrium ice melting curve (Gable et al., 1950). The dashed and the dotted lines represents a parameterization for homogeneous nucleation (Koop et al., 2000).

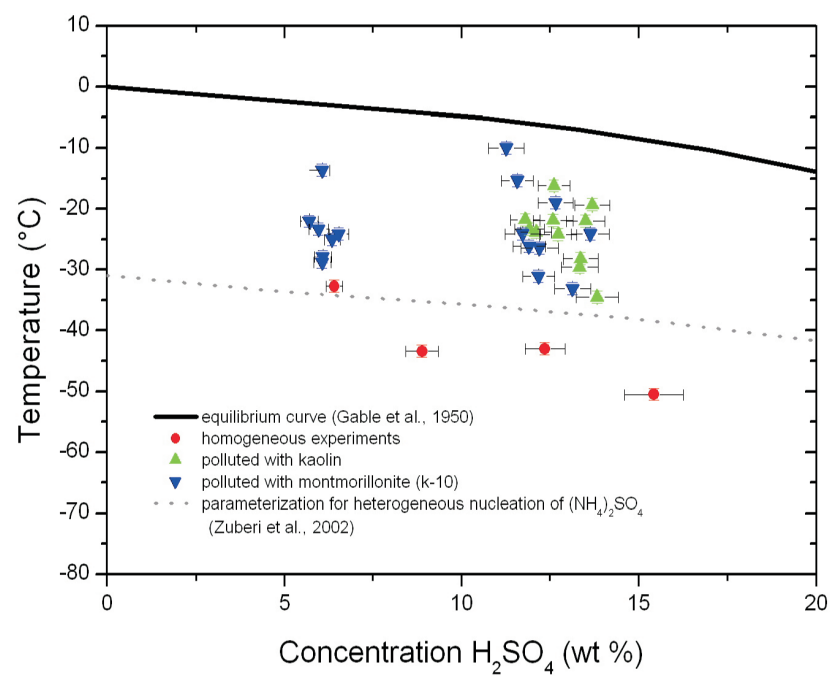

Fig. 7. Freezing temperatures of the sulphuric acid solution versus the concentration in $\mathrm{wt} \%$, droplets containing inclusions of kaolin and montmorillonite (K-10) compared to the pure solution, together with the equilibrium ice melting curve (Gable et al., 1950). The dotted line represents a parameterization for heterogeneous nucleation of $\left(\mathrm{NH}_{4}\right)_{2} \mathrm{SO}_{2}-\mathrm{H}_{2} \mathrm{O}$ droplets induced by kaolinte and montmorillonite $(\mathrm{K}-10)$.

as dashed and dotted lines. In the concentration range between $6-8 \mathrm{wt} \%$, the pure solution can be supercooled down to $-33^{\circ} \mathrm{C}$. With the presence of graphite the freezing temperature increases by $5-6^{\circ} \mathrm{C}$. Montmorillonite KSF-particles in the droplet lead to freezing temperatures $20^{\circ} \mathrm{C}$ higher than 
Table 2. Freezing temperatures of binary sulphuric acid/water solution containing inclusions of the particles graphite (gr), kaolin (ka), montmorillonite KSF (mKSF), montmorillonite K-10 (mK-10), respectivly.

\begin{tabular}{|c|c|c|c|c|c|}
\hline $\begin{array}{c}\mathrm{H}_{2} \mathrm{SO}_{4} \\
{[\mathrm{wt} \%]} \\
+(\mathrm{gr})\end{array}$ & $\begin{array}{l}\mathrm{T}_{\text {freeze }} \\
{\left[{ }^{\circ} \mathrm{C}\right]} \\
+/-1{ }^{\circ} \mathrm{C}\end{array}$ & $\begin{array}{c}\text { Volume } \\
{\left[\times 10^{-3} \mathrm{~cm}^{3}\right]} \\
<+/-5 \%\end{array}$ & $\begin{array}{c}\mathrm{H}_{2} \mathrm{SO}_{4} \\
{[\mathrm{wt} \%]} \\
+(\mathrm{mKSF})\end{array}$ & $\begin{array}{l}\mathrm{T}_{\text {freeze }} \\
{\left[{ }^{\circ} \mathrm{C}\right]} \\
+/-1{ }^{\circ} \mathrm{C}\end{array}$ & $\begin{array}{c}\text { Volume } \\
{\left[\times 10^{-3} \mathrm{~cm}^{3}\right]} \\
<+/-5 \%\end{array}$ \\
\hline $5.6 \pm 0.2$ & -12.6 & 3.0 & $5.7 \pm 0.2$ & -12.7 & 3.3 \\
\hline $5.7 \pm 0.2$ & -21.6 & 5.0 & $5.8 \pm 0.2$ & -10.8 & 2.5 \\
\hline $5.8 \pm 0.2$ & -18.3 & 4.1 & $6.0 \pm 0.3$ & -10.3 & 3.6 \\
\hline $5.8 \pm 0.2$ & -22.2 & 3.8 & $6.2 \pm 0.2$ & -10.8 & 3.1 \\
\hline $5.9 \pm 0.3$ & -22.6 & 4.6 & $6.2 \pm 0.2$ & -12.8 & 3.7 \\
\hline $6.1 \pm 0.2$ & $-27.7^{*}$ & 4.3 & $11.3 \pm 0.5$ & -15.9 & 2.7 \\
\hline $6.2 \pm 0.2$ & -11.5 & 4.1 & $11.6 \pm 0.4$ & -13.8 & 4.5 \\
\hline $6.3 \pm 0.2$ & -21.1 & 2.2 & $11.6 \pm 0.5$ & -14.1 & 3.8 \\
\hline $6.4 \pm 0.2$ & -20.2 & 3.6 & $11.8 \pm 0.5$ & -15.4 & 4.0 \\
\hline $6.4 \pm 0.3$ & -16.7 & 2.4 & $12.0 \pm 0.4$ & -13.9 & 3.6 \\
\hline $6.4 \pm 0.3$ & -22.4 & 3.9 & $12.1 \pm 0.5$ & -18.3 & 3.2 \\
\hline $6.6 \pm 0.2$ & -23.5 & 4.0 & $12.2 \pm 0.4$ & -16.8 & 3.5 \\
\hline $6.8 \pm 0.3$ & $31.4^{*}$ & 3.0 & $12.4 \pm 0.6$ & -17.2 & 3.2 \\
\hline $11.8 \pm 0.5$ & -26.1 & 4.1 & $12.5 \pm 0.6$ & -14.5 & 3.4 \\
\hline $11.8 \pm 0.5$ & -28.1 & 3.9 & $12.7 \pm 0.5$ & -12.6 & 3.2 \\
\hline $11.9 \pm 0.5$ & -27.5 & 3.6 & & & \\
\hline $12.0 \pm 0.4$ & -25.1 & 4.3 & & & \\
\hline $12.1 \pm 0.4$ & -25.4 & 2.8 & & & \\
\hline $12.4 \pm 0.5$ & -29.5 & 3.4 & & & \\
\hline $12.6 \pm 0.5$ & -30.7 & 3.4 & & & \\
\hline $12.9 \pm 0.5$ & -27.8 & 3.6 & & & \\
\hline $13.4 \pm 0.5$ & $-31.4^{*}$ & 4.1 & & & \\
\hline $\begin{array}{c}\mathrm{H}_{2} \mathrm{SO}_{4} \\
{[\mathrm{wt} \%]}\end{array}$ & $\begin{array}{c}\mathrm{T}_{\text {freeze }} \\
{\left[{ }^{\circ} \mathrm{C}\right]}\end{array}$ & $\begin{array}{c}\text { Volume } \\
{\left[\times 10^{-3} \mathrm{~cm}^{3}\right]}\end{array}$ & $\begin{array}{c}\mathrm{H}_{2} \mathrm{SO}_{4} \\
{[\mathrm{wt} \%]}\end{array}$ & $\begin{array}{c}\mathrm{T}_{\text {freeze }} \\
{\left[{ }^{\circ} \mathrm{C}\right]}\end{array}$ & $\begin{array}{c}\text { Volume } \\
{\left[\times 10^{-3} \mathrm{~cm}^{3}\right]}\end{array}$ \\
\hline$+(\mathrm{mK}-10)$ & $+/-1^{\circ} \mathrm{C}$ & $<+/-5 \%$ & $+(\mathrm{ka})$ & $+/-1^{\circ} \mathrm{C}$ & $<+/-5 \%$ \\
\hline $5.7 \pm 0.3$ & -22.1 & 2.2 & $11.8 \pm 0.4$ & -21.8 & 4.1 \\
\hline $6.0 \pm 0.3$ & -23.3 & 2.8 & $11.9 \pm 0.4$ & -23.4 & 4.9 \\
\hline $6.1 \pm 0.2$ & -13.6 & 5.8 & $12.1 \pm 0.4$ & -23.9 & 4.7 \\
\hline $6.1 \pm 0.2$ & $-28.8^{*}$ & 2.7 & $12.6 \pm 0.6$ & -21.9 & 3.7 \\
\hline $6.1 \pm 0.2$ & -27.9 & 4.1 & $12.6 \pm 0.4$ & -16.2 & 5.2 \\
\hline $6.4 \pm 0.2$ & -25 & 3.0 & $12.7 \pm 0.5$ & -24.2 & 4.0 \\
\hline $6.5 \pm 0.3$ & -24.2 & 3.7 & $13.3 \pm 0.5$ & $-29.6^{*}$ & 3.6 \\
\hline $11.3 \pm 0.5$ & -10 & 3.9 & $13.4 \pm 0.5$ & $-28.2^{*}$ & 3.5 \\
\hline $11.6 \pm 0.4$ & -15.3 & 4.0 & $13.5 \pm 0.5$ & -22 & 4.8 \\
\hline $11.7 \pm 0.5$ & -24.1 & 5.6 & $13.7 \pm 0.5$ & -19.3 & 4.1 \\
\hline $11.9 \pm 0.5$ & -26.2 & 3.1 & $13.8 \pm 0.6$ & $-34.6^{*}$ & 3.7 \\
\hline $12.2 \pm 0.5$ & $-31.1^{*}$ & 3.6 & & & \\
\hline $12.2 \pm 0.5$ & -26.4 & 4.2 & & & \\
\hline $12.7 \pm 0.5$ & -19 & 4.3 & & & \\
\hline $13.1 \pm 0.5$ & $-33.1^{*}$ & 3.5 & & & \\
\hline $13.6 \pm 0.5$ & -24.1 & 3.1 & & & \\
\hline
\end{tabular}

*these droplets contained only very few particles, so they could be frozen homogeneously.

that of the pure solution. The two measurements with the lowest freezing temperatures containing graphite are probably frozen homogeneously, because only few particles in the droplets were observed. This indicates the need for further experiments for which droplets with known numbers of contaminating particles are prepared.
Since the droplets studied in this paper consist of binary sulfuric acid water solutions the possible cover of the soot particles with $\mathrm{H}_{2} \mathrm{SO}_{4}$ probably does not play a role in the heterogeneous freezing process. Only the polycyclical organics present at the surface of the soot particles may influence the freezing. In this respect our experiments are incomplete 
and future experiments should be performed with combustion generated soot particles. Here too caveats exist because the nature of the combustion process itself influences the properties of the resulting soot particles. In this respect our experiments show that plain soot graphite already influences the heterogeneous freezing. Whether the presence of organics further enhances (or suppresses) this influence is left open here. Probably the organic coating detaches itself and goes to the surface of the liquid drop, thereby making it possible for the active surface of the particle to come in direct contact with the liquid and cause heterogeneous freezing. This has been suggested by Diehl et al. 1998, where soot particles from a kerosene burner where found to be poor contact nuclei but good immersion nuclei (presumably while they were coated with organics).

Figure 7 shows a diagram similar to that in Fig. 6, where the green triangles represents the droplets containing kaolin and the blue triangles those containing montmorillonite $\mathrm{K}$ 10. The dotted line in Fig. 7 represents a parameterization for heterogeneous nucleation of $\left(\mathrm{NH}_{4}\right)_{2} \mathrm{SO}_{4}$ droplets loaded with kaolinite and montmorillonite (K-10 with enhanced surface area) by Zuberi et al. (2002). Their results cannot directly be compared with the results in this paper, because the droplet composition is different. But in general the heterogeneous freezing temperatures are higher than those found by Zuberi et al. This can probably be accounted for by considering the differences in drop volumes between those used in the experiments cited and the ones used in the present study. An interesting observation is that Zuberi et al. (2002) made one common fit for heterogeneous freezing induced by both kaolinte and montmorillonite (K-10). We also found that the heterogeneous nucleation temperatures for these two materials are quite similar. In contrast using another variety of montmorillonite (KSF), which does not have an increased surface area, we found still higher heterogeneous freezing temperatures (see Fig. 6). Most likely this efficient heterogeneous nucleation at higher temperatures is due to the fact that the montmorillonite (KSF) particles are larger and thereby have higher probability of having active sites. The physical properties of the used substances can be found in Table 3.

The detailed data showing freezing temperatures as a function of the sulfuric acid content and the droplet volumes are listed in Table 2 together with estimation of the experimental errors.

\section{Conclusions}

We presented in this paper a contact-less technique to investigate ice nucleation of supercooled droplets. The freezing experiments with sulfuric acid have shown that the pure solution droplets freeze at lower temperatures compared to the heterogeneous freezing temperatures of the droplets contaminated with particles. Mineral particles, which are produced in the large desert areas and are transported in the up-
Table 3. Physical properties of the substances used as heterogeneous freezing nuclei.

\begin{tabular}{ccc}
\hline material & size $(\mu \mathrm{m})$ & surface area $\left(\mathrm{m}^{2} / \mathrm{g}\right)$ \\
\hline Graphite & $1-2$ & \\
Kaolin & $3-4$ & \\
Montmorillonite (K-10) & $3-4$ & $220-270$ \\
Montmorillonite (KSF) & $20-25$ & $20-40$ \\
\hline
\end{tabular}

per troposphere, are able to influence the freezing behaviour of cloud droplets. Soot particles that are directly emitted from aircraft engines into the UT/LS, can probably also influence the freezing of cloud droplets. This could be of importance for the microphysics of UT/LS-clouds containing supercooled droplets or mixed phase clouds. Here one should keep in mind that our experiments were carried out with graphite particles instead of combustion generated real soot. In addition the number concentration of such graphite nuclei were not compared against similar concentrations of soot particles in cloud droplets. Whether this affect the significance of such nucleation processes in an atmospheric context needs to be addressed by further laboratory experiments as well as field studies.

By means of this new levitation technique we are able to simulate the freezing processes which are responsible for contrail development (Penner et al., 1999). We are able to investigate the influence of different kinds of aerosols to the immersion freezing of droplets. Furthermore, organic substances can be added to the droplets, which change their surface tension and because of that (might) have influence on their freezing characteristics. Another application of the levitator is the investigation of ice nucleation in the contact mode. The aerosol particles can be brought in the surrounding of the droplet and induce contact freezing, when the particle hit the droplets surface. The visualisation of the freezing process itself will be possible after some optical rearrangements. This will contribute to recently raised issues in the literature concerning the initiation of the freezing process from the interior or the surface of the droplet. Also the studies on the influence of organic surfactants on the freezing can be performed. Thus this new device represents a technique of considerable potential for single droplet experiments.

Acknowledgements. This work in part was financially supported by the BMBF (01LO9523/6). We thank B. Luo for his code to determine the density for the sulphuric acid solution and for the calculation of the homogeneous freezing temperatures according to the parameterization of Koop et al., 2000.

Edited by: S. T. Martin 


\section{References}

Bertram, A. K., Patterson, D. D., and Sloan, J. J.: Mechanisms and temperatures of the freezing of sulphuric acid and aerosols measured by FTTR extinction spectroscopy, J. Phys. Chem., 103, 2376-2383, 1996.

Burtscher, H.: Measurement and Characteristics of Combustion Aerosols with special consideration of Photoelectric Charging and Charging by Flame Ions, J. Aerosol Sci., 23, 549-595, 1992.

Carleton, K., Sonnenfroh, D., Rawlins, W., Wyslouzil, B., and Arnold, S.: Freezing behaviour of single sulphuric acid aerosols suspended in a quadrupole trap, J. Geophys. Res., 102, 60256034, 1997.

Charlson, R. J. and Ogren, J. A.: The atmospheric cycle of carbon, in: Particulate carbon: Atmospheric Life Cycle, edited by Wolff, G. T. and Klimisch, R., Plenum Press, New York, 1982.

DeMott, P. J.: An exploratory-study of ice nucleation by soot aerosols, J. Appl. Meteor., 29, 1072-1079, 1990.

DeMott, P. J., Chen, Y., Kreidenweis, S. M., Rogers, D. C., and Sherman, D. E.: Ice formaton by black carbon particles, Geophys. Res. Lett., 26, 2429-2432, 1999.

Diehl, K. and Mitra, S. K.: A laboratory study of the effects of a kerosene burner exhaust on ice nucleation and evaporation of ice crystals, Atmos. Environ., 32, 3145-3151, 1998.

Diehl, K., Matthias-Maser, S., Mitra, S. K., and Jaenicke, R.: The ice nucleating ability of pollen. Part II: Laboratory studies in immersion and contact freezing modes, Atmos. Res., 61, 125-133, 2002.

Gable, C. M., Betz, H. F., and Maron, S. H.: Phase equilibria of the system sulphuric trioxide-water, J. Amer. Chem. Soc., 72, 14451448, 1950.

Hoffer, T.: A laboratory investigation of droplet freezing, J. Met., 18, 766-778, 1961.

Hung, H. M., Malinowski, A., and Martin, S. T.: Kinetics of heterogeneous ice nucleation on the surfaces of mineral dust cores inserted into aqueous ammonium sulfate particles, J. Phys. Chem. A, 107, 1296-1306, 2003.

Kay, J. E., Tsemekhman, V., Larson, B., Baker, M., and Swanson, B.: Comment on evidence for surface-initiated homogeneous nucleation, Atmos. Chem. Phys., 3, 1439-1443, 2003,

SRef-ID: 1680-7324/acp/2003-3-1439.

Koop, T., Huey, P. Ng., Molina, L. T., and Molina, M. J.: A new technique to study aerosol phase transitions: the nucleation of ice from $\mathrm{H}_{2} \mathrm{SO}_{4}$ aerosols, J. Phys. Chem. A, 102, 8924-8931, 1998.

Koop, T., Luo, B., Biermann, U., Crutzen, P., and Peter, T.: Freezing of $\mathrm{HNO}_{3} / \mathrm{H}_{2} \mathrm{SO}_{4} / \mathrm{H}_{2} \mathrm{O}$ solutions at stratospheric temperatures: nucleation statistics and experiments, J. Phys. Chem., 101, 11171133, 1997.

Koop, T., Luo, B. P., Tsias, A., and Peter, T.: Water activity as the determinant for homogeneous ice nucleation in aqueous solutions, Nature, 406, 611-614, 2000.

Krämer, B.: Laboruntersuchungen zum Gefrierprozess in polaren Stratosphären-wolken, Dissertation, FU Berlin, 1998.
Lahaye, J.: Particulate Carbon from the gas phase, Carbon, 30, 309314, 1992.

Luo, B. P., Krieger, U. K., and Peter, T.: Densities and refractive indices of $\mathrm{H}_{2} \mathrm{SO}_{4} / \mathrm{HNO}_{3} / \mathrm{H}_{2} \mathrm{O}$ solutions to stratospheric temperatures, Geophys. Res. Lett., 23(25), 3707-3710, 1996.

Martin, S. T., Salcedo, D., Molina, L. T., and Molina, M. J.: phase transformations of micron-sized $\mathrm{H}_{2} \mathrm{SO}_{4} / \mathrm{H}_{2} \mathrm{O}$ particles studied by infrared spectroscopy, J. Phys. Chem. B, 101(27), 5307-5313, 1997.

Mason, B.: Ice-nucleating properties of clay minerals and stony meteorites, Quart. J. Roy. Meteor. Soc., 86, 552-556, 1960.

Murphy, D. M., Thomson, D. S., and Mahoney, M. J.: In-situ measurements of organics, meteoritic material, mercury, and other elements in aerosols at 5 to 19 kilometers, Science, 282, 16641669, 1998.

Penner, J. E., Lister, D. H., Griggs, D. J., Dokken, D. J., and McFarland, M.: Aviation and the global atmosphere, Intergovernmental Panel on Climate Changes, Cambridge University Press, 1999.

Pitter, R. and Pruppacher, H. R.: A wind tunnel investigation of freezing of small water drops falling at terminal velocity in air, Quart. J. Roy. Meteor. Soc., 99, 540-550, 1973.

Prenni, A. J., Wise, M. E., Brooks, S. D., and Tolbert, M. A.: Ice nucleation in sulphuric acid and ammonium sulfate particles, J. Geophys. Res., 106, 3037-3044, 2001.

Pueschel, R. F., Blake, D., Snetsinger, K., Hansen, A. D. A., Verma, S., and Kato, K.: Black carbon (soot) aerosol in the lower stratosphere and upper troposphere, Geophys. Res. Lett., 19, 16591662, 1992.

Sheridan, P., Brock, L., and Wilson, J.: Aerosol particles in the upper troposphere and lower stratosphere: Elemental composition and morphology of individual particles in northern latitudes, Geophys. Res. Lett., 21, 2587-2590, 1994.

Tabazadeh, A., Djikaev, Y. S., and Reiss, H.: Surface crystallization of supercooled water in clouds, Proc. Natl. Acad. Sci., 99, 25, $15873-15878,2002$.

von Blohn, N.: Experimentelle Untersuchungen der Eiskeimfähigkeit verschiedener Pollenarten im Immersions- und Kontaktgefrierprozeß, Diploma Thesis, Institut für Physik der Atmosphäre, Mainz, 60-68, 2003.

Vortisch, H., Krämer, B., Weidinger, I., Wöste, L., Leisner, T., Schwell, M., Baumgärtel, H., and Rühl, E.: Homogeneous freezing nucleation rates and crystallization dynamics of single levitated sulphuric acid solution droplets, Phys. Chem. Chem. Phys., 2, 1407-1413, 2000.

Zuberi, B., Bertram, A. K., Koop, T., Molina, L. T, and Molina, M.: Heterogeneous freezing of aqueous particles induced by crystallized $\left(\mathrm{NH}_{4}\right)_{2} \mathrm{SO}_{4}$, ice and letovicite, J. Phys. Chem., 105, 64586464, 2001.

Zuberi, B., Bertram, A. K., Cassa, C. A. T., Molina, L. T, and Molina, M.: Heterogeneous nucleation of ice in $\left(\mathrm{NH}_{4}\right)_{2} \mathrm{SO}_{4}{ }^{-}$ $\mathrm{H}_{2} \mathrm{O}$ particles with mineral dust immersions, Geophys. Res. Lett., 29, 10.1029/2001 GL014289, 2002. 